\title{
PERFORMANCE OPTIMISATION ON WAITING TIME USING QUEUEING THEORY IN AN ADVANCED MANUFACTURING ENVIRONMENT
}

\author{
G. Salawu ${ }^{1 \#}$, G. Bright ${ }^{1 *} \&$ C. Onunka ${ }^{2}$
}

\section{ARTICLE INFO}

\section{Article details}

Submitted by authors 19 Aug 2019 Accepted for publication 3 Aug 2020 Available online $\quad 14 \mathrm{Dec} 2020$

\section{Contact details}

* Corresponding author brightg@ukzn.ac.za

Author affiliations

1 Department of Mechanical Engineering, University of KwaZulu-Natal, Durban, South Africa

2 Department of Mechanical Engineering, Mangosuthu University of Technology, Durban, South Africa

\# The author was enrolled for a PhD Eng. (Mechanical) degree in the Department of Mechanical Engineering, University of KwaZulu-Natal, Durban, South Africa

\section{ORCID® identifiers}

G. Salawu

https://orcid.org/0000-0002-7436-6721

G. Bright

https://orcid.org/0000-0003-4386-0329

C. Onunka

https://orcid.org/0000-0002-5707-9368

DOI

http://dx.doi.org/10.7166/31-4-2217

\section{ABSTRACT}

Queueing is a common phenomenon in various stages of manufacturing systems and some other organisations. Queueing usually reduces the time required by managers and manufacturers to complete a desired task. The queueing mathematical theory is a viable tool for analysing a waiting line model. This research presents the implementation of robots at the packaging stage of a virtual manufacturing scenario in which mathematical models were used to describe each stage of the manufacturing process. Some suitable parameters and operating conditions were assumed, and the Newton-Raphson iteration formula was implemented for numerical analysis of the models. Simulation was carried out to achieve optimal values that could yield efficient productivity. The optimisation process gave an outcome that adequately showed how queueing can be managed in the packaging stage in an advanced manufacturing environment.

\section{OPSOMMING}

Toustaan is 'n algemene verskynsel tydens verskeie stadiums van vervaardigingstelsels en ander organisasies. Toustaan verminder gewoonlik die tyd benodig deur bestuurders en vervaardigers om ' $n$ bepaalde taak te voltooi. Wiskundige toustaanteorie is 'n lewensvatbare benadering om die toustaan model te ontleed. Hierdie artikel bespreek die implementering van robotte tydens die verpakkingsfase van 'n virtuele vervaardigingscenario aan. Wiskundige modelle is gebruik om elke stadium van die vervaardigingsproses te beskryf. 'n Paar geskikte parameters en werktoestande is aangeneem en die Newton-Raphson iterasie formule is toegepas vir numeriese analise van die modelle. Die simulasie is uitgevoer om optimale waardes wat doeltreffende produktiwiteit lewer te identifiseer. Die optimeringsproses se resultaat toon aan dat toustaan bestuur kan word in die verpakkingsfase van 'n gevorderde vervaardigingsomgewing.

Performance optimisation during a manufacturing process is an essential tool that supports manufacturers in achieving a cost-effective manufacturing system. This process involves proper monitoring and modification of some operating conditions that can help to enhance productivity. The effective implementation of optimisation tools during a selected manufacturing process also helps to improve the financial performance of a product in a competitive environment [1]. The goal of a manufacturer is to bring in innovative ideas that can support improvement, productivity, and throughput. The proper presumption of an effective manufacturing process is a useful measure that can identify and diagnose performance problems in an advanced manufacturing environment. An essential factor that determines efficient productivity is the time spent during a production stage [2]. Production time requires adequate control measures that can assist manufacturers to obtain production output at a reduced cost. The packaging stage of manufacturing, where much time is spent, is a critical stage. During the packaging phase, products are always placed in a queue while awaiting the next available servers to pick them up. This increases the 
waiting time and the overall time of production, and can have a great impact on the overall efficiency of the production process. Adequate control of the waiting time has become a major concern among manufacturers: waiting time results in queueing during manufacturing, as a process or product spends more than the required time waiting for an activity or process to be completed. It is important, therefore, to understand how to deal effectively with problems associated with queues resulting from products awaiting server operation. The research aims to study performance optimisation on waiting time using the queuing theory to analyse a packaging stage model in order to control the waiting time. Mathematical models were developed to study and predict queue length in the packaging stage of a virtual manufacturing scenario. Some parameters were assumed to solve the waiting line model, using the mathematical expression developed from the queueing mathematical theory of Leonard Kleinrock [3]. Mathematical modelling - in describing a manufacturing process using the queuing theory for system analysis - can suggest a quick and efficient solution to manufacturing problems [4]. The Newton-Raphson iteration formula served as the simulation tool used to analyse and generate various expressions and to find a numerical solution; from that the best operating parameters that can yield adequate productivity were obtained. The results were studied, and are presented in graphical form. The outcome from the study presents a suitable model and mathematical expression that can be useful to manufacturers making decisions in the early stage of manufacturing.

\section{LITERATURE REVIEW}

A queue is a common scenario at various stages during manufacturing in an advanced manufacturing environment. A queue is a phenomenon that leads to congestion, and the cost of waiting affects the productivity level in an advanced manufacturing environment [5]. in [6], it was deduced that the Packaging stage requires an effective measure to reduce the time spent from the initial stage of manufacturing to the final stage. Elkhodr, Shahrestani, and Cheung [7], also confirmed the effectiveness of implementing mathematical modelling in predicting behaviour at various stages in an advanced manufacturing environment. Mathematical models were successfully used to make decisions and solve various problems at different stages of manufacturing before implementation in a real-world scenario [8]. In (A, I and A 2014), the Queuing theory was effectively used as an analytical tool to solve waiting line models. The theory was successfully used to predict the average waiting time of customers in a restaurant, and the expected numbers of servers who can attend to customers in a specific period. And in the research by S.R.C Mohammad, Rahman T, R.K Mohammad, \& Mohammad R.K [10], a waiting line model - consisting of the arrival stage, the waiting time, and a service rate - was effective analysed using the queueing mathematical theory.

Similarly, the queuing theory was found to be an efficient tool for predicting the behaviour of a manufacturing system. The manufacturing process was further simulated to attain optimal productivity [11]. From the research of Kamel S, Abdel-Akher M, Jurado F, [12], mathematical modelling and simulation ere effective in studying the power control devices and voltage level of a power system. The outcome of their findings suggests that the use of the Newton Raphson method as the simulation tool gave more accurate results than some other related methods [12]. A study by Amaral and Cadosol [13], suggested that the Newton Raphson method was effective in estimating the optimal condition of an electrolytic capacitor. Similarly, in [14], the behaviour of a photovoltaic model was studied with further analysis using the Newton Raphson iteration method. Nearly accurate results were obtained compared with the real-life scenario [14]. This makes the Newton-Raphson iteration method a suitable simulation tool when finding optimal solutions to a manufacturing problem. Mathematical models have also been used to study various types of manufacturing processes, and to predict certain behaviours of some components that can affect productivity. Toshiba S, Sanjay K, \& Anil K.S. [15] conducted research in an attempt to solve long queues in the banking system. The waiting line model was developed to study the behaviour of the reoccurring congestion. The queuing theory was successfully used as an analytical tool to suggests a quick solution to analyze the waiting line models [15]. Related attempts to solve manufacturing problems using different manufacturing models were also carried out by Seyed Hosseini, Reza, Kamalpour, and Zang [16]. The queuing theory was implemented to analyse a mathematical model to study an inventory system. The study showed how effective the queuing theory could be in analyzing a system with substitute flexibility. In other research, the queuing theory was used to study the congestion measures of vessels arriving at a river port. The queuing theory was used to analyse and suggest a solution that can be used in the real-life scenario to improve service performance, and to control congestion that could lead to a larger queue [5]. Anupana and Solankin [17], used the queuing theory to study and analyse a manufacturing scenario that often experiences server breakdown [17]. Their research suggested a more effective measure to prevent further breakdown, and showed the effectiveness of the queueing theory in analyzing and finding solutions that can predict an optimal service system for optimal productivity. 
Other mathematical models are also available to study and making decisions in an advanced manufacturing environment. Gankjaesh and Manish [18], formulated a time-based mathematical model for solving production scheduling problems. It was found to be an effective tool for controlling the time spent in getting a product to the final stage [18]. Cheol [19] evaluated the performance of a generic algorithm using an integer programming model. An unrelated parallel machine scheduling problem was solved by designing a model that can provide an optimal solution to reduce the total completion time during the manufacturing process [19]. Mohamed [20] established a progressive model that can solve complex and large-scale manufacturing problems. The model proposed in the study was used in application such as supply chain management, production planning and scheduling, and continuous process improvement. in [21], the progressive close loop approach was used to study the relationship between two types of mathematical modelling, (The dependency structure matrix (DSM) and stochastic optimisation modelling). Similarly, the stochastic optimisation modelling yielded higher productivity than the dependency structure matrix in (Guo 2013). A Pareto optimisation model was developed to solve multi-objective order scheduling problems in the manufacturing industry. The model was effective for solving scheduling processes in the manufacturing line. In [23], a Markov model was implemented in the decision making of a multi-stage manufacturing system to study which machine parameters could yield optimal productivity. The production process was analysed efficiently under a Bernoulli's condition to obtain an optimal output.

Based on the previous studies, the queuing theory was successfully effective in analysing various modelling techniques in manufacturing. In this study, the packaging stage of a virtual manufacturing scenario was studied to determine the effect of waiting time on productivity. Robots, as a disruptive technology, were implemented during the packaging stage to study the performance and to determine the optimum service rate required by the server (Robot) to yield optimum productivity. The model analysis was done using the queuing mathematical theory, and the numerically analysis and simulation were carried out using the Newton-Raphson iteration method.

\section{SPECIFICATIONS OF THE FANUC ROBOT USED FOR THE PACKAGING PROCES}

The $\mathrm{M}-10 \mathrm{i}-A$ Fanuc robot used for the packaging task is designed with six degrees of freedom, and is capable of moving in various directions. The maximum load capacity is $10 \mathrm{~kg}$, its arm reach is $1422 \mathrm{~mm}$, and its weight is $130 \mathrm{~kg}$, with a repeatability of $\pm 0.03^{\circ}$ [24]. Owing to its high degree of rotation and repeatability, the throughput rate is high when implemented to perform tasks in an advanced manufacturing environment. Programmable software is designed along with it to coordinate its operation, as required by the operator [24]. The camera in the operating system immediately senses the parts arriving and sends a signal to the robot (server) for immediate pick up. The implementation of a robot/manipulator to automate a manufacturing task effectively saves on the costs of production, increases throughput, controls waiting times, and reduces the lead time in an advanced manufacturing environment [25] [26] [27] [28] [29].

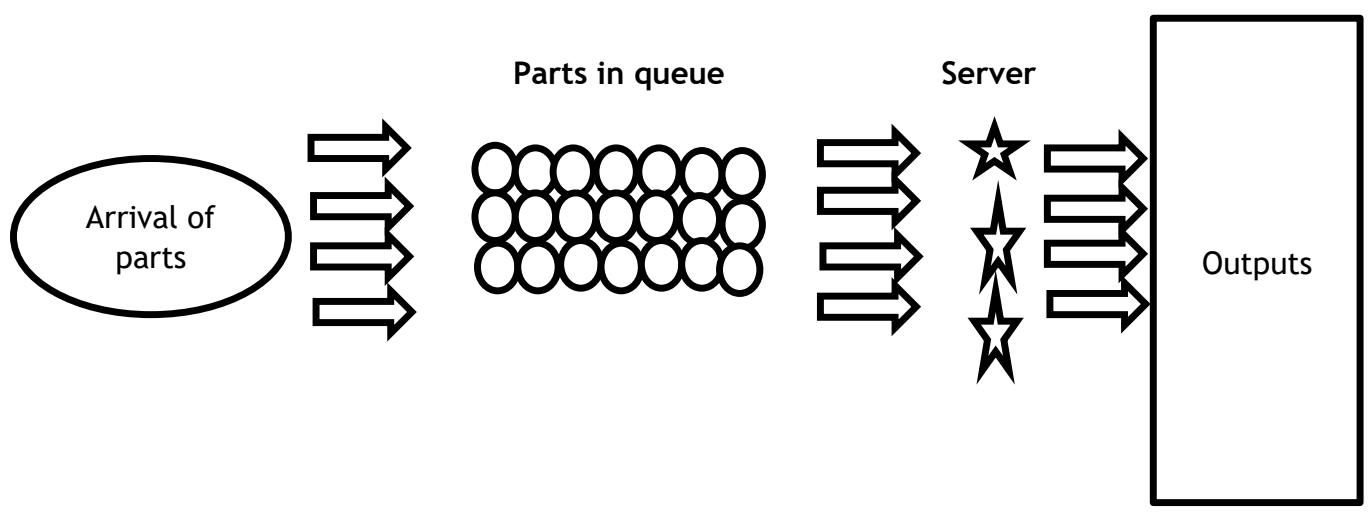

Figure 1: Schematic diagram of products in a queue during packaging stage.

\section{METHODOLOGY}

A virtual multi-stage manufacturing scenario was considered in which products arrived at the packaging stage from various stations, awaiting the response of the server (robots). During this process, the products 
that arrived from various stations accumulated, resulting in a queue. Classical models were used to describe and study the manufacturing process. The models were further analysed using the queueing mathematical model. Some parameters were assumed to represent various conditions that build up in the manufacturing system, with some assumed operating values. The analysis of the model resulted in the development of suitable mathematical equations. The assumed values were computed into the equations and solved numerically using the Newton-Raphson iteration method. The results obtained were compared with each other to obtain the best operating conditions and parameters that solved the waiting line model, and were represented graphically. The steps in achieving the aim of the research are summarised below.

Step 1. A production process to be studied was selected (packaging stage).

Step 2. Classical models were used to study and make decisions in the packaging stage of the virtual manufacturing scenario. The queueing mathematical theory was used to analyse the classical models. Parameters were chosen, along with some operating conditions and assumed values, that could effectively describe the manufacturing system. Parameters that were studied in the waiting line model included the cost of the robot/hour $\left(C_{p}\right)$, the cost of waiting per hour $\left(C_{w}\right)$, the average number of products arriving from the machine per unit time $\left(\lambda_{i}\right)$, the packaging rate, which represents the service rate per unit of time measured per hour $(\mu)$, the average number of products in the queue $\left(L_{s}\right)$, and the utility factor of the server, which is the $\operatorname{robot}\left(\rho_{n}\right)$.

Step 3. With step 2 above, suitable equations were chosen for data exploration, and a suitable expression was developed. Assumed values were fitted into the equation and solved using the NewtonRaphson iteration formula.

Step 4. The Newton Raphson iteration formula was used as a simulation tool to achieve close approximate values that were used to analyse the scenario numerically. This gave various approximate values which were compared against each other. Results were further presented in a graphical form.

\subsection{Operating parameters}

The following parameters were used to describe the behavior of the proposed model.

$n=$ maximum number of machines available in the production line

$\lambda_{i},=$ The arrival rate of each product for the machine, where $i=1,2,3 \ldots \ldots \ldots \ldots, n$

$\mu_{j}(t)=$ The packaging rate for robots used per unit of time, where $j=1,2,3 \ldots . . m$

$m=$ The maximum number of robots employed for packaging in the production line

$\rho_{n}=$ The productivity rate of each robot

$\rho=$ The utility factor for the manufacturing system

$C_{p}=$ The server production cost per hour

$C_{w}=$ The cost of each product waiting in the queue

$L_{s}=$ The average waiting time for products in the queue

( $C_{p}=\mathrm{R} 2 /$ hour, $C_{w}=\mathrm{R} 0.1 /$ hour, $\lambda_{i}=5$ units/hour for 10 machines, $\mu=2$ units per hour)

\subsection{Proposed model for evaluation of system productivity of a multiple server system using queueing theory}

A multi-stage manufacturing system was proposed in this study. A robot, as a disruptive tool, was implemented as a server to perform a packaging task. A multi-stage manufacturing system is common in modern manufacturing systems. It requires multiple stages and stations to complete a production process or service [30]. An illustration of the multi-stage production system is given in Figure 1: it describes a manufacturing scenario with products in a queue waiting for a server (robot) to attend to them. An equal rate of arrival was assumed for all the machines.

However, manufacturers experience delays in some stages of the process that result in waiting lines and queues of products/processes. The packing stage is one that experiences queueing and that requires adequate measures to curtail it. The queueing theory proposed by Leonard Kleinrock [3] is an effective tool, and was chosen for this work. Classical mathematical models were developed to study and describe a virtual manufacturing scenario where heavy traffic was experienced at the packaging stage of a manufacturing process. The queue resulted from multiple products arriving at a point and awaiting action from the server. The trade-off point was set between the number of machines employed for production and the throughput level. The server rate and the queueing time were two parameters used to determine the trade-off point in the manufacturing system.

The servers (robots) were assumed to perform their task at the same rate, based on a 'first come, first served' (FIFO) mode. During this process, the system performance was modelled into a Poisson distribution 
function where the service time was exponentially distributed. The queueing theory analytical tool was used to generate various expressions that were analysed using the Newton Raphson iteration formula. Some assumptions were made along with some parameters that were used to represent the various operating conditions. These values were implemented in the equations and solved numerically. The iteration results gave varying approximate values from which the best operating parameters were chosen. The illustration of the whole scenario is presented using equations 1-29.

The production arrival rate is given as:

$$
\sum_{i=1}^{n} \lambda_{i}(\mathrm{t})=n \lambda(t)
$$

The number of products arriving is expressed as:

$$
N=\lambda T
$$

For this study, a discrete value was assumed. The total number of products that arrived for packaging per unit time is expressed as:

$$
N=n \lambda_{t} \mathrm{xt}
$$

which implies that the number of products that arrived per unit time is expressed as:

$$
t=\frac{N}{\Lambda}
$$

The production rate for each robot $=\mu_{j} \mathrm{xt}$

Total product packed by available robots $=\mu_{j}(t) \times t \times m$

Similarly, for efficient performance optimisation in the manufacturing process, suitable equations that can give optimum results are required. For the packaging stage, $\eta \geq s$, and the product on queue is $\eta-s$. Then

$$
\mu_{n}=\mathrm{s} \mu
$$

The utility factor of the system, denoted by $\rho$, is the ratio of the rate at which work enters the system to the maximum rate at which the system can perform this work. For a single server case, it is given by:

$$
\rho=\lambda \mu
$$

During the packaging phase, the utility factor of the robots is expressed in equation (9).

$$
\rho_{n}(t)=\frac{\lambda_{i}(\mathrm{t})}{\mu_{j}(t)}
$$

The mean queueing time required by each robot and the production rate of each robot is expressed in equation (10).

$$
p_{j}(t)=\left(\lambda_{i}+\mu_{j}\right) \rho_{n}(t)+\lambda_{i} \rho_{n-1}(t)+\rho_{n+1}(t)
$$

Therefore, for the whole robot the productivity $\rho_{n}(t)$ is given by:

$$
\rho_{n}(t)=\left(\sum_{i=1}^{n} \lambda_{i}+\sum_{j=1}^{n} \lambda_{i} \mu_{j}\right) \rho_{n}(t)+\sum_{i=1}^{n} \lambda \rho_{n-1}(t)+\sum_{j=1}^{m} \mu_{j} \rho_{n+1}(t) \text { for } t \rightarrow \infty
$$

For a discrete value of time $\mathrm{t}$ :

$$
\rho_{n}(t)=\rho_{n}(\mathrm{t})+\lambda n \rho_{n-1}(t)+\mu(t) \rho_{n+1}(t)
$$

The waiting time is expressed as: 


$$
W=\sum_{j=1}^{m} \mu_{j}-\sum_{j=1}^{m} \lambda_{i}, \quad \mathrm{w}=\frac{1}{\mathrm{~m}_{\mu_{j}}-\mathrm{n}_{\lambda i}}
$$

to calculate the total cost of production, given that the time spent by the robot on production is $=C_{p}$, and the cost of waiting for each product to be packaged $=C_{w}(t)$. The average waiting time for products queueing is given by:

$$
L_{s}=\frac{1}{\mathrm{~m}_{\mu_{j}}-\mathrm{n}_{\lambda i}} \times \mathrm{t}
$$

The waiting time per unit hour is expressed as:

$$
L_{s}=\frac{\mathrm{n}_{\lambda i}}{\mathrm{n}_{\lambda t-\mathrm{m}_{\mu_{j}}}}
$$

The cost of production $\mathrm{T}$ is expressed in terms of the waiting time

$$
T=m c p \mu_{j}+c_{w} \rho_{n} w L_{s}
$$

We substitute equations (9), (13), and (15) into equation (16); the production cost is expressed as:

$$
T=m C_{p} \mu_{j}+c_{w}\left(\frac{\lambda_{i}}{\mu_{j}}\right)\left(\frac{1}{\mathrm{~m}_{\mu_{j}}-\mathrm{n}_{\lambda i}}\right)\left(\frac{\mathrm{n}_{\lambda i}}{\mathrm{~m}_{\mu_{j}}-\mathrm{n}_{\lambda i}}\right)
$$

The production cost gives:

$$
T=m C_{p} \mu_{j}+C_{w}\left(\frac{\lambda_{i}^{2}}{\left(\mu_{j}\left(\mathrm{~m}_{\mu_{j}}-\mathrm{n}_{\lambda i}\right)^{2}\right.}\right)
$$

To optimise the performance of the system on waiting time, equation (9) was reduced by differentiating it from the service rate of each robot.

$$
C_{p}+\frac{\lambda^{2}\left[(\mu-\lambda)^{2}+2 \mu(\mu-\lambda)\right]}{\mu^{2}(\mu-\lambda)^{4}}=0
$$

The final equation for optimal service is given as:

$$
C_{p} \mu^{5}-3 C_{p} \mu^{4} \lambda+3 C_{p} \mu^{3} \lambda^{2}-C_{p} \mu^{2} \lambda^{3}+3 \mu \lambda^{2} C_{w}-C_{w} \lambda^{3}=0
$$

\section{MODEL SIMULATION USING THE NEWTON-RAPHSON METHOD}

The Newton-Raphson iteration method is a powerful tool that uses ideas from calculus to solve numerical equations. Its application is based on finding an approximate value for the root of a valued function of $x$. When the Newton-Raphson equation is employed, there is a great reduction in the errors that are likely to occur when calculating roots of functions. This gives it an advantage over other methods, and makes it a suitable tool for this present research. It is widely used in finding zeros of an arbitrary equation, where the specific root of a function depends on the initial value.

The analysis that led to the generation of the Newton-Raphson equation is given below.

If the root of the equation is $r$, let $x_{0}$ be the estimate value of $r, h$ is a measure of the approximate value of $x_{0}$ from the exact value.

Where $r=x_{0}+h, h=r-x_{0} . h$ is very small and its linear approximation is given as

$$
\begin{gathered}
0=f(r)=f\left(x_{0}+h\right) \\
\approx f\left(x_{0}\right)+h f^{\prime}\left(x_{0}\right)
\end{gathered}
$$


This can only be valid if, $f^{\prime}\left(x_{0}\right)$ is approximately equal to zero.

Therefore the estimated value $x_{1}$ of $r$ gives

$$
\begin{gathered}
h \approx \frac{f\left(x_{0}\right)}{f^{\prime}\left(x_{0}\right)} \\
r=x_{0}+h \approx x_{0}-\frac{f\left(x_{0}\right)}{f^{\prime}\left(x_{0}\right)}
\end{gathered}
$$

$$
x_{1}=x_{0}-\frac{f\left(x_{0}\right)}{f^{\prime}\left(x_{0}\right)}
$$

$x_{2}$ also follows the same trend as $x_{1}$

$$
x_{2}=x_{1}-\frac{f\left(x_{1}\right)}{f^{\prime}\left(x_{1}\right)}
$$

For a required number of $x, x_{n}$ is the next approximate value. Therefore $x_{n+1}$ is given by

$$
x_{n+1}=x_{n}-\frac{f\left(x_{n}\right)}{f^{\prime}\left(x_{n}\right)}
$$

For the service rate of the server $(\mu)$, the Newton Raphson iteration for analysing the model can be presented as:

$$
\mu_{n+1}=\mu_{n}-\frac{f\left(\mu_{n}\right)}{f^{\prime}\left(\mu_{n}\right)}
$$

The Newton-Raphson Poisson distribution equation is given in equation (28), and the derivative is given in equation (29). The Newton-Raphson iteration formula is presented in its first order and second order in equations 28 and 29 respectively [31].

$$
\begin{gathered}
f(\mu)=C_{p} \mu^{5}-3 C_{p} \mu^{4} \lambda+3 C_{p} \mu^{3} \lambda^{2}-C_{p} \mu^{2} \lambda^{3}+3 \mu \lambda^{2} C_{w}-C_{w} \lambda^{3} \\
f^{\prime}(\mu)=5 C_{p} \mu^{4}-12 C_{p} \mu^{3} \lambda+9 C_{p} \mu^{2} \lambda^{2}-2 C_{p} \mu \lambda^{3}+3 \lambda^{2} C_{w}
\end{gathered}
$$

In this study, assumed values $\left(C_{p}=\mathrm{R} 2 /\right.$ hour, $C_{w}=\mathrm{R} 0.1 /$ hour, $\lambda_{i}=5$ units/hour for 10 machines, $\mu=2$ units per hour) were implemented to solve and analyse the models using the derived equations. The outcomes were iterated and close approximate values were obtained.

\section{DISCUSSION}

The queueing mathematical model was successfully used to study how the performance of a manufacturing system can achieve optimal productivity. Simulation results provided us with suitable values that were used for the graphical representation of the results. The graph plotted - along with the set of operation parameters and conditions - gave an efficient output that can be implemented in a real-life manufacturing scenario. The graph of Figure 2 illustrates the performance of the robots in the packaging stage of manufacturing against the arrival rate of the products. The graph clearly shows that the packaging rates increased as the arrival rate also increased. This implies that the number of robots assumed in the decisionmaking for the proposed model was suitable to solve the waiting line model. There was no congestion, and there was an easy flow of arriving parts such that the available servers were able to generate adequate productivity. Similarly, Figure 3 shows the graph of waiting time plotted against the number of robots implemented during the packaging of products. The outcome shows that the average waiting time reduced with the availability of an increased number of servers (robots). The graph of Figure 4 presents the relationship between the utility factor and the number of robots used. The representation shows that the ratio of the maximum demand for the robot during the packaging stage corresponded to the available number of robots to yield optimal output. This shows the smooth behaviour of the proposed models. 


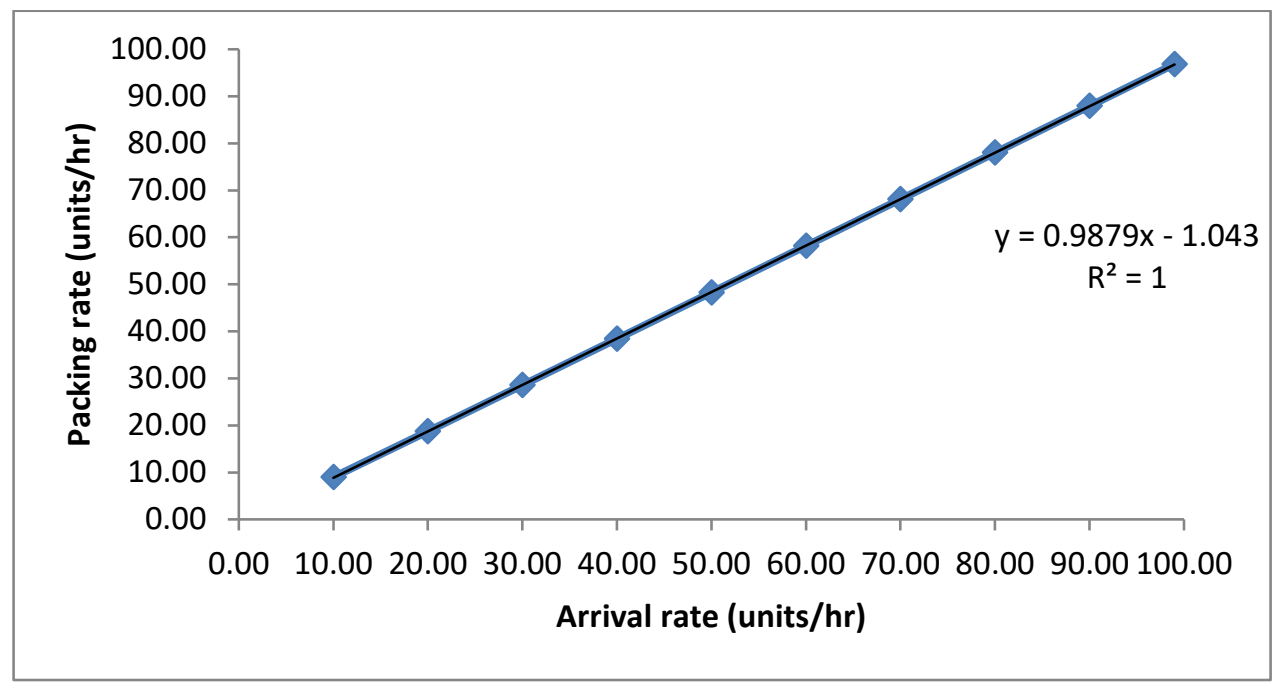

Figure 2: Packaging rate of products against the arrival rate

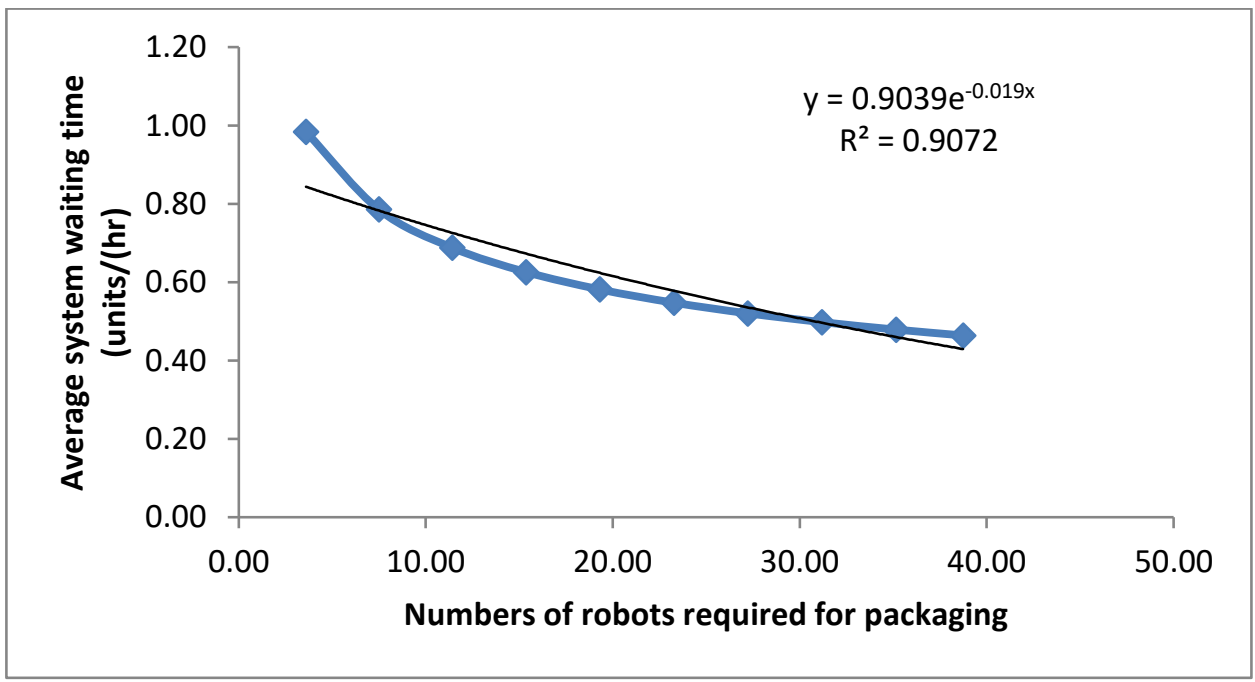

Figure 3: Average waiting time against number of robot used for packaging

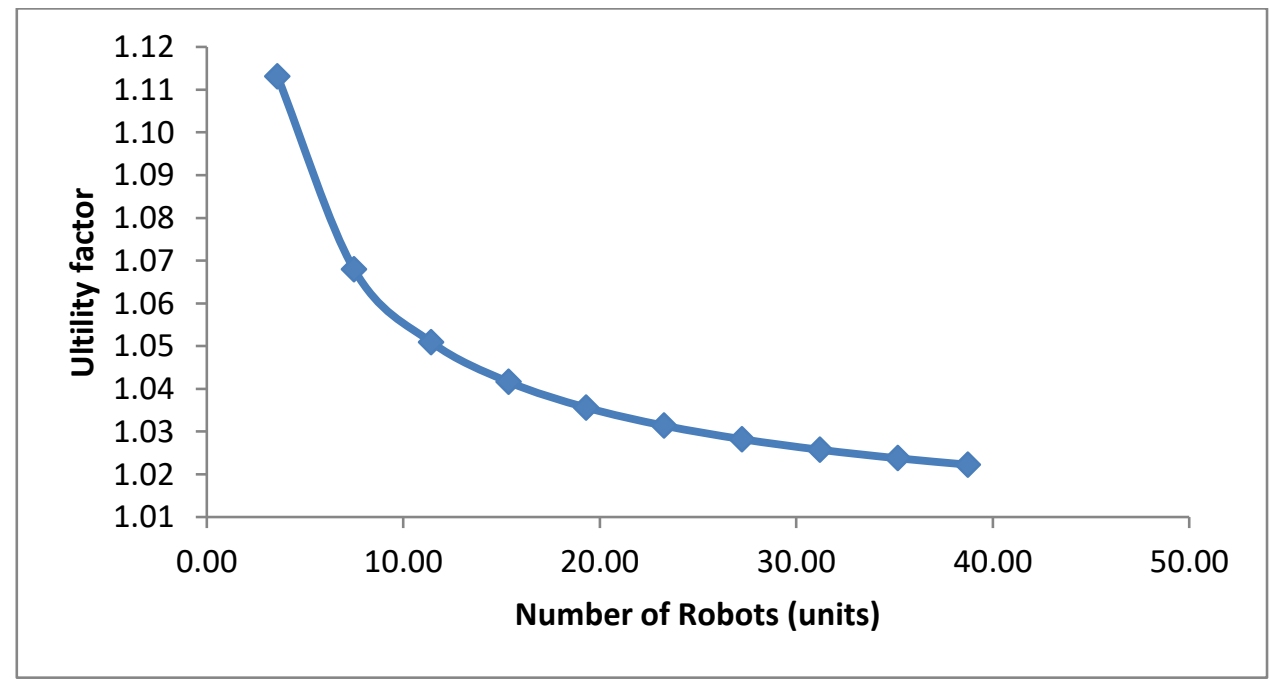

Figure 4: The utility factor against number of robots used 
The models best describe the behaviour of the products during the arriving stage and the packaging stage of the virtual manufacturing scenario. The description of the process gives the structure of the service facility required for the arrival stage modelling. Queueing is a complicated phenomenon that has a great impact on the throughput rate in an advanced manufacturing environment. Adequate control measures of the waiting time are required by employing a practical tool that can adequately control and analyse a waiting line model. The queueing theory has been shown to be an effective analytical tool that can be used to solve a waiting line model. The $\mathrm{M} / \mathrm{M} / \mathrm{S}$ queue model is described in this present work; $\mathrm{M} / \mathrm{M} / \mathrm{s}$ model has its servers arranged in a parallel form where the service time at each station is identical following the same exponential law. Classical models were used to describe a virtual manufacturing scenario where robots as a disruptive technology were used as servers in the packaging stage. Various equations were used to describe the manufacturing scenario in which the average queueing time was presented. The average queueing time was further differentiated to optimise the performance of each robot with its corresponding queue. The outcome gave a general equation that was further analysed using the Newton-Raphson iteration method. The outcome gave an output free of queueing. This produced the graph in Figure 2, which shows a minimum waiting time. The results confirmed that the suggested model can be suitable for use when the queueing time needs to be controlled during the packaging stage in a real-life manufacturing scenario.

\section{ACKNOWLEDGEMENT}

The author gratefully acknowledges support from TETFUND Nigeria (TETFUND/AST\&D/ POLY/OFFA/2017/VOL1). The author would also like to acknowledge the support from JW Nelson for providing funding for this research work.

\section{REFERENCES}

[1] Ran, L., Xiaolei, X., Kaiye Y., Qiaoyu H. 2017, A survey on simulation optimisation for the manufacturing system operation. International Journal of Modelling and Simulation, Vol. 38, pp. 116-122.

[2] Reza A \& Amir H.B. 2014, Evaluation of queuing systems for knowledge-based simulation ofEvaluation of queuing systems for knowledge-based simulation of construction processes, Automation in Construction, 47, pp. 37-49.

[3] Kleinrock, L. 1975, Queueing systems. Volume I, Theory, New York. Wiley-Interscience.

[4] Wilson, $M \&$ Charle, R.N. 2017, simulation and optimization of the materials flow of a multi-product assembling plant," Procedia Manufacturing 8 , p. 59 - 66.

[5] Branislav, D., Nam-Kyu, P., Nenad, D.Z., \& Romeo, M. 2012, Mathematical Models of Multiserver Queuing System for Dynamic Performance Evaluation in Port. Mathematical Problems in Engineering, pp. 1-19.

[6] Mourtzis, D., Doukas, M., \& Bernidaki D. 2014. Simulation in manufacturing: Review and Challenges. Procedia CIRP, vol. 25, p. $213-229$.

[7] Elkhodr, M., Shahrestani, S., \& Cheung, H. 2016. "emerging wireless technologies in the internet of things: a comparative study. International Journal of Wireless \& Mobile Networks (IJWMN), 8, pp. 67-82.

[8] Sushil, G., Gyan, B., Thapa, R., Prasad. G., Sergei, S. 2017. A Survey on Queueing Systems with Mathematical Models and Applications," American Journal of Operational Research, vol. 7, no. 1, pp. 1-14.

[9] Manjurul, A., Raisul, I., \& Ashikul A. 2014. Study of queuing system of a busy Restaurant and a Proposed Facilitate Queuing System," IOSR Journal of Mechanical and Civil Engineering (IOSR-JMCE), vol. 11, no. 6, pp. 31-35.

[10] Rahman, M.T., \& Kabir M.R. 2013. Solving Of waiting lines models in the bank using queuing theory model the practice case: Islami bank Bangladesh limited, chawkbazar branch, Chittagong," vol. 10, no. 1, pp. $22-29$.

[11] Martin, A., Abdul-Aziz., A.R., Kwame, A., \& Francis T.O. 2013. Application of queuing theory to vehiculartraffic at signalized intersection in Kumasi-Ashanti Region, Ghana. American International Journal of Contemporary Research. 3(7), pp. 23-29.

[12] Kamel, S., Abdel-Akher, M., \& Jurado, S. 2013. Modeling and analysis of voltage and power control devices in current injections load flow method. Electric Power Components and Systems, 41, pp. 324-344.

[13] Amaral, A.M., \& Cardoso A.J.M. 2008. Using Newton-Raphson Method to Estimate the Condition of Aluminum Electrolytic Capacitors," in 34th Annual Conference of IEEE Industrial Electronics.

[14] Adel, A.A., Elbaset, A., Ali, H \& Abd-El Sattar., M. 2015. Modeling of Photovoltaic Module Based on Two-Diode Model. 17th International Middle East Power Systems Conference, Mansoura University.

[15] Toshiba, S., Sanjay, K \& Anil, K.S. 2013. A Study of Queuing Model for Banking System, International Journal of Industrial Engineering and Technology, 5 (1), pp. 21-26.

[16] Seyedhoseini. S.M., Reza, R., Kamalpour E., \& Zang E. 2015. Application of queuing theory in inventory systems with substitution flexibility, journal of Industrial Engineering International , 11 (4), pp. 37-44.

[17] Anupama, A., S. 2016. Mathematical Modeling and Analysis of Finite Queueing System with Unreliable Single Server, IOSR Journal of Mathematics (IOSR-JM) , 12, pp. 8-14.

[18] Ganesh, D.M., \& Manish J. 2015. Mathematical Modeling of Production Scheduling Problem: A Case Study for Manufacturing Industry, International Journal of Science Technology \& Engineering , pp. 224-226. 
[19] Joo, C., \& Kim, B.C. M.J and B. S.K, 2015. Hybrid genetic algorithms with dispatching rules for unrelated parallel machine scheduling with setup time and production availability production availability, Computers and Industrial Engineering, 85, pp. 102-109.

[20] Ismail, M.. 2013. Progressive modeling. The Process, the Principles, and the applications, Procedia Computer Science, 16, pp. 39-48.

[21] Ashger, U., Ahmad, R., \& Butt S. 2013. Mathematical modeling of manufacturing process plan, optimization analysis with stochastic and DSM modeling techniques. Advanced Materials Research, 816, pp. 1174-1180.

[22] Guo, Z.X., Wong, W.K. Zhi, Li., Peiyu, R. 2013. Modeling and Pareto optimization of multi-objective order scheduling problems in production planning. Computers \& Industrial Engineering, 64, pp. 972-986.

[23] Du, S., Xu, R., \& Li, L. 2018. Modeling and analysis of multiproduct multistage manufacturing system for quality improvement. IEEE Transactions on Systems, Man, and Cybernetics: Systems, 48, pp. 801-820.

[24] FANUC. FANUC high industrial speed machine Accessed Online: http://www.fanuc.ed>robot $>$ fanuc-m-10.a-125. July 22, 2020.

[25] Lartkultanon, P., \& Pham, Q. 2018. A certified-complete bimannual manipilation planner IEEE Transactions on Automation Science and Engineering, 15(3), pp. 1355-1368.

[26] Wan, W., et al. 2019. A re-grasp planning component for object reorientation. Autonomous Robot,43(5), pp. 11011115.

[27] Domski, W., Mazur, A. \& Kaczmerck, M. 2019. Extended factitious force approach for control of a mobile manipulator moving on unknown terrain. Journal of Intelligent \& Robotic Systems, 93, pp. 699-712.

[28] Kowalczyk, W. 2019. Rapid navigation function control for two-wheeled mobile robots. Journal of Intelligent \& Robotic Systems, 93, pp. 687-697.

[29] Nguyen, H., Le, T., Nguyen, D., Le, T., Lang, T. \& Ngo, T. 2020. Development of 3-DOF force feedback system using spherical arm mechanism and MR brakes. International Journal of Mechanical Engineering and Robotics Research, 9(2), pp. 170-176.

[30] Zhang, F. \& Butt, S. 2016. A systematic approach to quality oriented product sequencing for multistage manufacturing systems. Mathematical Problems in Engineering, 2016, pp. 1-9.

[31] Seeger, M.W. 2008. Cross-validation optimization for large scale structured classification kernel methods. Journal of Machine Learning Research, 9, pp. 1147-1178.

[32] Kleinrock, L. 1975. Queueing systems, Volume I: Theory. New York: Wiley-Interscience. 